\title{
PENGARUH KECERDASAN EMOSIONAL TERHADAP KEMAMPUAN MENGELOLA KONFLIK DI LEMBAGA PEMASYARAKATAN KLAS IIA WANITA TANGERANG |
}

\author{
Mirrah Apsari Nubi \\ Jurusan Psikologi, Fakultas Ilmu Pendidikan, Universitas Negeri Jakarta \\ Jl. Rawamangun Muka, Jakarta Timur \\ E-mail: miemirra@,hotmail.com
}

\begin{abstract}
This study aims to determine the effect of emotional intelligence with the ability to manage a conflict. The experiment was held in Tangerang. The method used is ex post facto method with quantitative approach. Population sample of inmates or residents guided the study sample as many as 362 and as many as 70 people with a random sampling technique. The instrument used is to test the ability to manage conflict as the dependent variable and the scale on emotional intelligence as independent variables. From anareg equation $\hat{\mathrm{Y}}=1,86+0,16 \mathrm{X}$, Fcount $=47.19$, Ftable $=3.99$, because the regression is Fcount $>$ of Ftable is very significant. To determine the linearity seen as Fcount $=1.14$, and Ftable $=1.76$, so it means the form of linear regression Fcount $<$ Ftable. For Ttest, the path coefficient of 0.640 with a determinant coefficient of $r^{2}=$ 0.409 . It's means that emotional intelligence gave $40.9 \%$ of the ability to manage conflict. Tcount got (6.88)> Ttable (1.67) at $\alpha 0.05$. So the hypothesis is "There is the any influence of emotional intelligence with ability of Managing Conflict".
\end{abstract}

Keywords: influence, emotional intelligence, the ability to manage conflict, prisoners

\section{PENDAHULUAN}

\begin{abstract}
Sehubungan dengan percepatan perubahan dunia dan merebaknya pengaruh globalisasi, Lembaga Pemasyarakatan mempunyai peranan yang cukup penting dan strategis dalam ikut serta mewujudkan terciptanya masyarakat dan manusia Indonesia yang lebih baik. Setiap kehidupan bermasyarakat tentu saja tidak dapat lepas dari aturan-aturan ataupun kaidah hukum yang berlaku dimasyarakat. Bila seseorang melangggar aturanaturan dan hukum, baik pelanggaran ringan hingga berat, maka akan dikenakan sanksi yang berlaku di masyarakat.
\end{abstract}

Pemberian hukuman bagi narapidana atau warga binaan adalah untuk memberikan efek jera dan penyesalan dengan mengetahui kesalahan yang telah diperbuatnya. Menimbulkan rasa derita atas penderitaan dan kesendirian serta hilangnya rasa kebebasan yang ia rasakan di dalam LAPAS (lembaga pemasyarakatan), sehingga ia akan berbuat baik kembali di masyarakat.
Narapidana atau warga binaan adalah terpidana yang menjalani pidana hilang kemerdekaan di Lembaga Pemasyarakatan (Priyatno, 2006). Seorang yang dipenjara berarti telah terbukti melakukan pelanggaran hukum, yang tentu saja tidak disukai dan ditentang oleh masyarakat. Narapidana atau warga binaan yang ada di Lembaga Pemasyarakatan dibedakan berdasarkan jenis kelaminnya, yaitu pria dan wanita

Dari data yang diperoleh peneliti saat melakukan praktek kerja psikologi di LAPAS Klas IIA Wanita Tangerang, peneliti mendeteksi adanya konflik atau permusuhan yang sering kali terjadi dilingkungan LAPAS antara sesama narapidana atau warga binaan. Konflik yang terjadi bisa dikarenakan sesuatu hal yang kecil, kesalahpahaman, ketidakcocokkan, pertentangan, permusuhan, perbedaan pendapat antara satu dengan yang lain, hal itulah yang menjadikan konflik terjadi di LAPAS. Menurut sebagian narapidana atau warga binaan yang berada di LAPAS bahwa menjalani hukuman didalam LAPAS tidaklah terlalu berat untuk mereka, akan tetapi konflik serta permusuhan dengan sesama narapidana atau warga binaan yang mereka 
rasakan berat untuk menjalani kesehariannya didalam LAPAS.

Lembaga Pemasyarakatan Klas IIA Wanita Tangerang memiliki visi dan misi yaitu sebagai berikut: Visi : Mewujudkan Manusia Yang Beriman, Bertaqwa, Aktif dan Produktif Serta Bertanggung Jawab Dalam Kehidupan Bermasyarakat. Misi : Melaksanakan Pembinaan Spiritual Baik Rohani maupun Jasmani Untuk Meningkatkan Kemandirian sebagai Manusia yang Bermartabat dan Mandiri.

Sebagian masyarakat menganggap bahwa seseorang yang masuk kedalam Lembaga Pemasyarakatan sudah pasti bersalah dan merupakan dosa besar. Padahal tidak jarang banyak orang yang masuk kedalam lembaga pemasyarakatan adalah korban dari ketidak mengertian mereka akan hukum. Berada didalam lembaga pemasyarakatan bukan membuat seseorang menjadi buruk, tujuan lembaga pemasyarakatan adalah membina para narapidana atau warga binaan agar dapat memiliki kemampuan dengan mengisi kegiatan dengan kegiatan yang bermanfaat dan dapat mereka aplikasikan setelah mereka keluar dari lembaga pemasyarakatan.

Narapidana atau warga binaan yang ada dalam di lembaga pemasyarakatan tentunya saling berhubungan, dan berinteraksi satu sama lain. Ketika interaksi tersebut berlangsung dapat terjadi kemungkinan konflik akibat adanya perbedaan pendapat, persaingan dan berbagai pertentangan.

Permasalahannya adalah pemahaman tehadap konflik kurang dipahami secara komprehensif. Keberanian pihak yang terlibat Konflik untuk mengelola Konflik tersebut masih dipengaruhi oleh persepsi konflik yang disfungsional sifatnya. Yaitu "Pertentangan antar kelompok yang mengganggu atau merintangi upaya pencapaian tujuan organisasi" (Gibson et.al. 2009). Konsekuensi konflik bisa destruktif atau negatif dan bisa juga konstruktif atau positif.

Lembaga pemasyarakatan seperti halnya organisasi lain, dalam perjalanan nya juga tidak luput dari masalah konflik, baik konflik yang terjadi di dalam maupun di luar lingkungan Lembaga pemasyarakatan, antara narapidana atau warga binaan dengan narapidana atau warga binaan lainnya, antara narapidana atau warga binaan dengan masyarakat, antara narapidana atau warga binaan dengan aparat yang ada di lembaga pemasyarakatan, maupun komponen lainnya yang terkait. Narapidana atau warga binaan, secara langsung atau tidak langsung juga terlibat di dalamnya berkenaan dengan adanya konflik. Bagaimana seorang narapidana atau warga binaan mengatur agar konflik tersebut dapat dikelola dengan baik dan dapat memberikan dampak yang positif bagi semua pihak atau sebaliknya.

Salah satu faktor yang mempengaruhi kemampuan mengelola konflik adalah Kecerdasan emosional. Kecerdasaan emosional merupakan komponen yang membuat seseorang menjadi pintar menggunakan emosi. Emosi manusia berada diwilayah dari perasaan lubuk hati, naluri yang tersembunyi, dan sensasi emosi yang apabila diakui dan dihormati, kecerdasaan emosional menyediakan pemahaman yang lebih mendalam dan lebih utuh tentang diri sendiri dan orang lain.

Narapidana atau warga binaan sebagai individu jika memandang dirinya sebagai orang yang tidak cukup mampu untuk mengelola konflik yang ada dan rendahnya kecerdasan emosi yang dimiliki, akan mengikut sertakan seluruh perasaan dan pengetahuannya dalam perilaku pengelolaan konflik di lembaga pemasyarakatan. Seluruh perasaan dan pengetahuan narapidana atau warga binaan akan mewarnai corak perilakunya, baik dalam pola interaksinya dengan para narapidana atau warga binaan maupun komponen lainnya. Kapasitas narapidana atau warga binaan dengan perasaan dan pengetahuan di atas akan menyulitkan dirinya dalam lingkungan lembaga pemasyarakatan tersebut. Narapidana atau warga binaan yang memiliki kecerdasan emosi yang rendah akan sulit mengelola konflik yang ada.

\section{METODE PENELITIAN}

\section{Sampel}

Sampel dalam penelitian ini adalah warga binaan LAPAS Klas IIA Wanita Tangerang. Sebanyak 70 orang yang dijadikan sampel penelitian.

\section{Instrumen}

\section{Skala Kemampuan Mengelola Konflik}

Instrumen Kemampuan Mengelola

Konflik dikembangkan atas beberapa indikator, yaitu: pengertian konflik, persaingan yang sehat, menghindar, akomodasi, kompromi. Instrument penelitian untuk kemampuan mengelola konflik sebagai atribut dari aspek kognitif selain juga sebagai atribut psikologis. Dari 20 soal, hanya 17 soal yang dapat digunakan untuk analisis lebih lanjut. Adapun skor untuk dari setiap item akan memiliki bobot satu untuk setiap jawaban yang 
benar. Sedangkan untuk item yang salah tidak mendapatkan nilai atau nol. Koefisien reliabilitasnya .85 .

\section{Skala Kecerdasan Emosional}

Instrumen Kecerdasan Emosional dikembangkan atas beberapa indikator, yaitu: kesadaran diri, pengelolaan diri, motivasi, dan empati. Dari 25 item yang ada hanya 17 item yang dapat dianalisis. Dengan koefisien reliabilitas sebesar .87 .

\section{HASIL DAN DISKUSI}

Analisis data yang dilakukan dalam penelitian ini dilakukan secara kuantitatif. Untuk mengetahui pengaruh kecerdasaan emosioan terhadap kemampuan mengelola konflik di LAPAS Klas IIA Wanita Tangerang. Perhitungan dilakukan dengan persamaan regresi sederhana.

Tabel 1

Persamaan Hasil Regresi

\begin{tabular}{|c|c|c|c|c|c|}
\hline Sumber & dk & (JK) & (RJK) & $\mathbf{F}_{\text {hitung }}$ & $\begin{array}{c}F_{\text {tabel }} \\
\alpha=0,05\end{array}$ \\
\hline Total & 70 & 10934 & & & \\
\hline Regresi b/a & 1 & 130,72 & 130,72 & $\begin{array}{c}47,19 \\
* *\end{array}$ & 3,99 \\
\hline $\begin{array}{c}\text { Tuna } \\
\text { Cocok }\end{array}$ & 24 & 72,39 & 3,02 & $1,14^{\mathrm{ns}}$ & 1,76 \\
\hline
\end{tabular}

\section{Grafik 1}

Persamaan regresi $\hat{\mathrm{Y}}=1,86+0,16 \mathrm{X}$. Diperoleh Fhitung $=47,19$ lebih besar dari pada Ftabel 3,99 pada $\alpha=0,05$. Karena Fhitung $>$ Ftabel maka persamaan regresi dinyatakan sangat signifikan. Untuk uji linieritas, diperoleh Fhitung $=1,14$ lebih kecil dari pada Ftabel $=1,76$ pada $\alpha=$ 0,05 . Karena Fhitung $<$ Ftabel maka sebaran titik yang terestimasi membentuk garis linier dapat diterima. Secara visual dapat terlihat pada gambar di bawah ini.

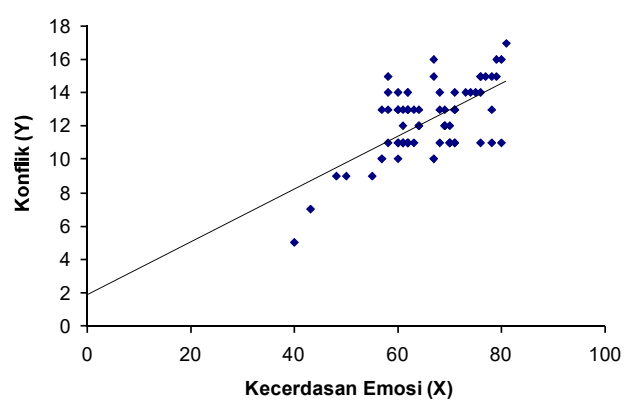

Grafik Persamaan Regresi $\hat{Y}=1,86+0,16 X$

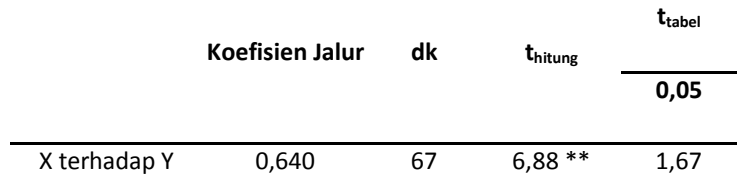

Tabel 2

Pengaruh Langsung Antar Variabel

Kecerdasan emosional mempengaruhi kemampuan mengelola konflik pada warga binaan di LAPAS Klas IIA Wanita Tangerang.

Kecerdasan emosional yang baik dapat membuat warga binaan mengelola konflik yang dialaminya dengan baik, dengan begitu konflik yang terjadi dapat terselesaikan dengan baik.

Hasil dari penelitian ini dapat memberikan gambaran bagaimana seseorang dengan kecerdasan emosional yang baik akan dapat mengelola konflik yang dihadapi. Sedangkan jka seseorang dengan kecerdasan emosional yang kurang akan kesulitan dalam mengelola konflik yang dihadapi.

\section{KESIMPULAN}

Berdasarkan hasil penelitian yang telah dilakukan dan dianalisis, maka dapat disimpulkan bahwa terdapat pengaruh Kecerdasan Emosional terhadap Kemampuan Mengelola Konflik pada narapidana atau warga binaan di Lapas Klas IIA Wanita Tangerang.

Penelitian ini pada dasarnya merupakan upaya untuk memahami pengaruh antara kecerdasan emosional terhadap kemampuan mengelola konflik narapidana atau warga binaan 
di Lembaga Pemasyarakatan Klas IIA Wanita Tangerang.

Upaya meningkatkan kecerdasan emosional dalam memberi kontribusi terhadap kemampuan mengelola konflik narapidana atau warga binaan di Lembaga Pemasyarakatan Klas IIA Wanita Tangerang, diharapkan untuk meningkatkan kualitas hubungan sosial narapidana atau warga binaan maupun komponen lainnya di Lingkungan LAPAS .

Dengan begitu warga binaan yang memiliki kecerdasan emosional yang cenderung baik maka dirinya dapat mengelola konflik dengan baik, namun sebaliknya jika warga binaan kurang memiliki kecerdasan emosional yang baik maka dirinya akan mengalami kesulitan untuk mengelola konflik.

Adapun kelemahan-kelemahan yang menjadi keterbatasan dalam penelitian ini antara lain ialah, penelitian ini hanya dibatasi pada variable kecerdasaan emosional dengan demikian tidak dapat mengungkap informasi lebih komprehensif tentang faktor faktor yang mempengaruhi kemampuan mengelola konfli, penelitian menggunakan instrument penelitian untuk kemampuan mengelola konflik sebagai atribut dari aspek kognitif selain juga sebagai atribut psikologis, dalam penelitian ini peneliti menemukan satu dua buah sampel yang memiliki keterbatasan kemampuan kognitif (dalam memahami dan membaca ataupun menulis) instrument yang diberikan dan ada beberapa sampel yang sedikit enggan untuk mengisi instrument yang diberikan oleh peneliti.

\section{Daftar Pustaka}

Atherton, C.R \& D.L Klemmark. (1999). Research Method in Social Work: An Introdution, dikutip (atau tidak langsung) oleh Irawan Suhartono, Metode Penelitian Sosial. Bandung Rosdakarya.

Barret, Jim \& Williams Geof. (2000). Tes Bakat Anda, terjemahan Tito Ananta Darwin Rasyid. Jakarta, Gaya Media Pratama.

Cooper, Robert K. \& Aryman Sawaf. (2002). Emosional dalam Kepemimpinan dan Organisasi, terjemahan Alex Tri Kuncoro. Jakarta, Gramedia Pustaka Utama.

Efendi, Agus. (2005). Revolusi Kecerdasan Abad 21, Kritik MI, EI, SQ dan Successful Intelligence atas IQ. Bandung, Alfabeta.
Gibson, James L. M. Ivanevich, James. R dan. Donnelly, Junior. (2009). Organisasi, terjemahan Djarkasih. Jakarta, Erlangga.

Goleman, Daniel. (2001). Kecerdasan Emosional, terjemahan T. Hermaya. Jakarta, Gramedia Pustaka Utama.

Graig, Jeanne A. (2004). Bukan Seberapa Cerdas Diri Anda Tetapi Bagaimana Anda Cerdas, alih bahasa Arvin Saputra. Batam, Interaksara.

Greenberg, Jerald \& A. Baron, Robert. (1993). Behaviour In Organization. USA, A Division of Simon \& Schuster, Inc.

Hendricks, William (1996). Bagaimana Mengelola Konflik, terjemahan Arif Santoso. Jakarta, Bumi Aksara.

Kapadila, Mala. (1998). Emotional Intelligence, a Work book for beginner. New Delhi, BPI.

Kartono, Kartini. (1991). Pemimpin dan Kepemimpinan. Jakarta, Rajawali Pers.

Kerlinger, Fred. N. (1986). Asas-Asas Penelitian Behavioral. Yogyakarta, Gajah Mada University Press.

Kinichi, Angelo \& Robert Kreitner. (2009). Organisational Behaviour. New York, McGraw.

Lussier, Robert N. (1996). Human Relations in Organizations A Skill Building Approach. USA, The Mc Graw-Hill Companies Inc.

Muhtadi, Ali. (2009). Model Pembelajaran Interpersonal-managemen konflik

Pritayno, Dwidja. (2006). Sistem Pidana Penjara di Indonesia. Bandung, PT Refika Aditama.

R, Rahayu. (2010) SPSS Versi 17.00. Bandung, Alfabeta.

Richard H, Richard. (1991) Structures Processes and Outcomes. New Jersey, Prentice Hall, Inc.

Robbins, Stephen P. (2003). Organisational Behaviour. Jakarta, Indeks.

R. Bootzin, Richard. H. Bower, Gordon. B. Zayonc, Robert dan Hall, Elizabeth. (1956) Psychology Today An Introduction. California, The Mc Graw-Hill Publishing Company. 
R. Meyer. (2004) Managing With Emotional Inteligence: It Takes Two To Tango. Kuala Lumpur, Golden Book Center SDN BHD.

Segal, Jeanne. (2001) Meningkatkan Kecerdasan Emosional, alih bahasa Dian Paramesti Bahar. Jakarta, PT. Citra Aksara.

Setiawan, Conny. A.S Munandar dan Utami.Munandar (1987) Memupuk Bakat dan Kreativitas Siswa Menengah. Jakarta, Gramedia Pustaka Utama.

Stoner, JamesA.F \& Charles Winkel. (1986). Manajemen, alih bahaasa Wilhelmus W. Bakowatum, Jakarta, CV Intermedia.

Sugiyono. Metode Penelitian Kuantitatif dan Kualitatif. Yogyakarta, PT. Bina Insan Cendikia.

Supranto. (2004) Analisis Multivariat Arti dan Interpretasi. Jakarta, Rineka Cipta.

Weisinger, Hendra. (1998) Emotional Inteligence at Work. San Fransisco, Josset Bass, Publisher.

Wright, Patrick M. \& A. Noe, Raymond. (1995). Management of Organizations. USA, United Status: Richard D. Irwin.

Yukl, Gary. (1994) Leadership in Organizations. New Jersey, Prentice Hall, Inc. 